\title{
ПОВЫШЕНИЕ ВОЗРАСТА МАТЕРИНСТВА: ПРЕИМУЩЕСТВА И РИСКИ НА ПУТИ РОСТА БЛАГОСОСТОЯНИЯ СЕМЬИ
}

Светлана АКСЁНОВА ${ }^{\odot}$, кандидат экономических наук, ведущий научный сотрудник, Институт демографии и социальных исследований имени М.В. Птухи, Национальная академия наук Украины

DOI: https://doi.org/10.36004/nier.cdr.2019.14-07 JEL CLASSIFICATION: J10, J12, J13.

В статье рассмотрены некоторые факторы, способствующие повышению возраста материнства. Откладывание рождения ребенка на старший возраст постепенно становится соџиальной нормой. Это четко проявляется в формировании общественной позищии относительно необходимости снижения рождаемости в самой младшей репродуктивной группе женщин и, особенно, у несовершеннолетних девушек, и сочиального предписания сначала получить высшее образование, приступить $\kappa$ построению профессиональной карьеры, занять определенную социальную позицию, и лишь после этого родить и воспитывать ребенка. В иелом, такая последовательность жизненных событий показала свои преимущества на пути роста благополучия семьи, одновременно слишком длительное откладывание рождения ребенка может привести к обратному эффекту.

Ключевые слова: средний возраст матери при рождении ребёнка, средний возраст матери при рождении первого ребёнка, подростковая рождаемость, откладывание рождений.

The article discusses some factors that contribute to increasing the age of motherhood. The postponement of fertility to the older age of women is gradually becoming social norm. This is clearly manifested in the formation of a public position regarding the need to reduce the birth rate in the youngest fertile group, particularly among adolescent, and the social prescription to firstly get a high level education, start building a professional career, take a certain social position, and after that give birth and to raise a child. In general, such a sequence of life events has shown advantages on the path to increasing family well-being, however too long delaying the birth of a child can lead to the opposite effect.

Key words: the mean age of mother at childbirth, the mean age of women at first birth, adolescent fertility, the postponement of childbirth.

Ученые различных научных направлений давно интересуются трансформационными процессами в рождаемости, разворачивающимися в той или иной стране по мере её социально-экономического развития. Исследования охватывают широкий диапазон взаимосвязей и факторов рождаемости на уровне отдельных индивидов, семей, социальных групп, а также на уровне всего населения. Появление возможности планировать определенные сферы жизнедеятельности, в частности деторождение, параллельно вызвало необходимость изучать факторы, влияющие на формирование репродуктивных установок, принятие решений о числе детей в семье и сроках их появления. Важным направлением исследований является изучение механизмов установления и закрепления в обществе норм поведения и культурных предписаний, которые влияют на репродуктивное поведение, в частности, на возраст женщины при рождении ребенка. Существование таких норм и предписаний и их различия между странами продемонстрировало Европейское социальное исследование, раунд 6, когда преобладающее большинство респондентов указали точный возраст, до которого девушке ещё рано становиться мамой, а также возраст, после которого женщине уже не следует рожать.

\footnotetext{
๑ Светлана Аксёнова, svitlana_aksyonova@yahoo.com
} 
Откладывать вступление в брак и рождение ребенка молодыми женщинами, ориентирующимися на получение высшего образования и освоение профессии, не только стало социально приемлемым и одобряемым поведением, но постепенно переходит в позицию ожидаемого и требуемого.

Украина длительный период принадлежала к странам с традицией раннего начала деторождения. Перелом тенденции произошел в середине 1990-х гг. Средний возраст матери при рождении ребенка стал постепенно повышаться и за два десятилетия вырос более, чем на 3 года, достигнув в 2018 г. 25,4 лет в случае рождения первенцев и 27,7 лет для всех очередностей рождения (Рuc. 1.).

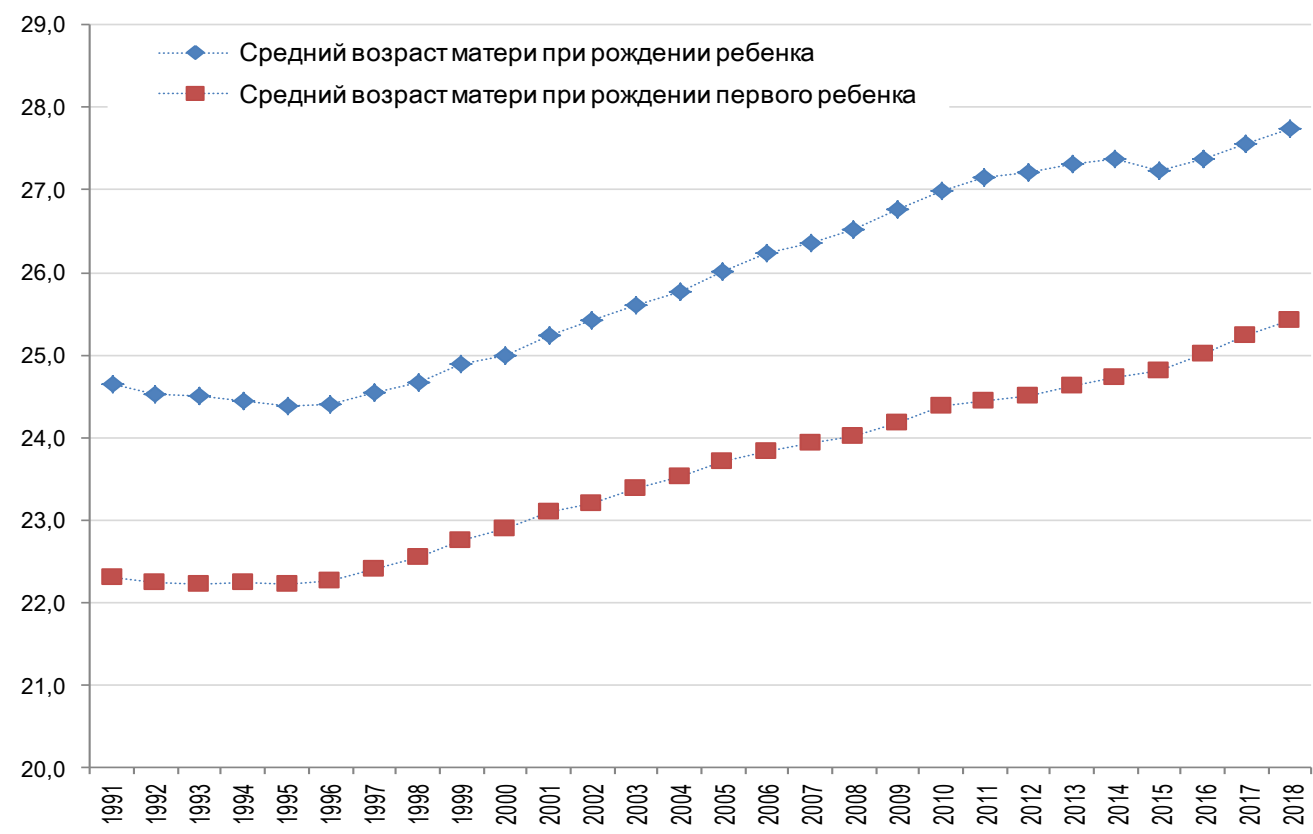

Рисунок 1. Средний возраст матери при рождении ребенка в Украине в 1991-2018 гг. Источник: Расчеты автора на основе данных Государственной службы статистики Украины

Несмотря на значительное повышение среднего возраста матери при рождении ребенка в Украине, значение показателя остается одним из самых низких не только среди развитых европейских государств, но и среди восточноевропейских соседей (Рuc. 2.). Особенно сильный контраст Украины наблюдается с такими странами как Ирландия, Испания, Италия, Швейцария, в которых средний возраст матери при рождении ребенка достигает 32 лет, а также Нидерланды, Швеция, Германии, Греции, Финляндии, Норвегии, где показатель превышает 31 год. 


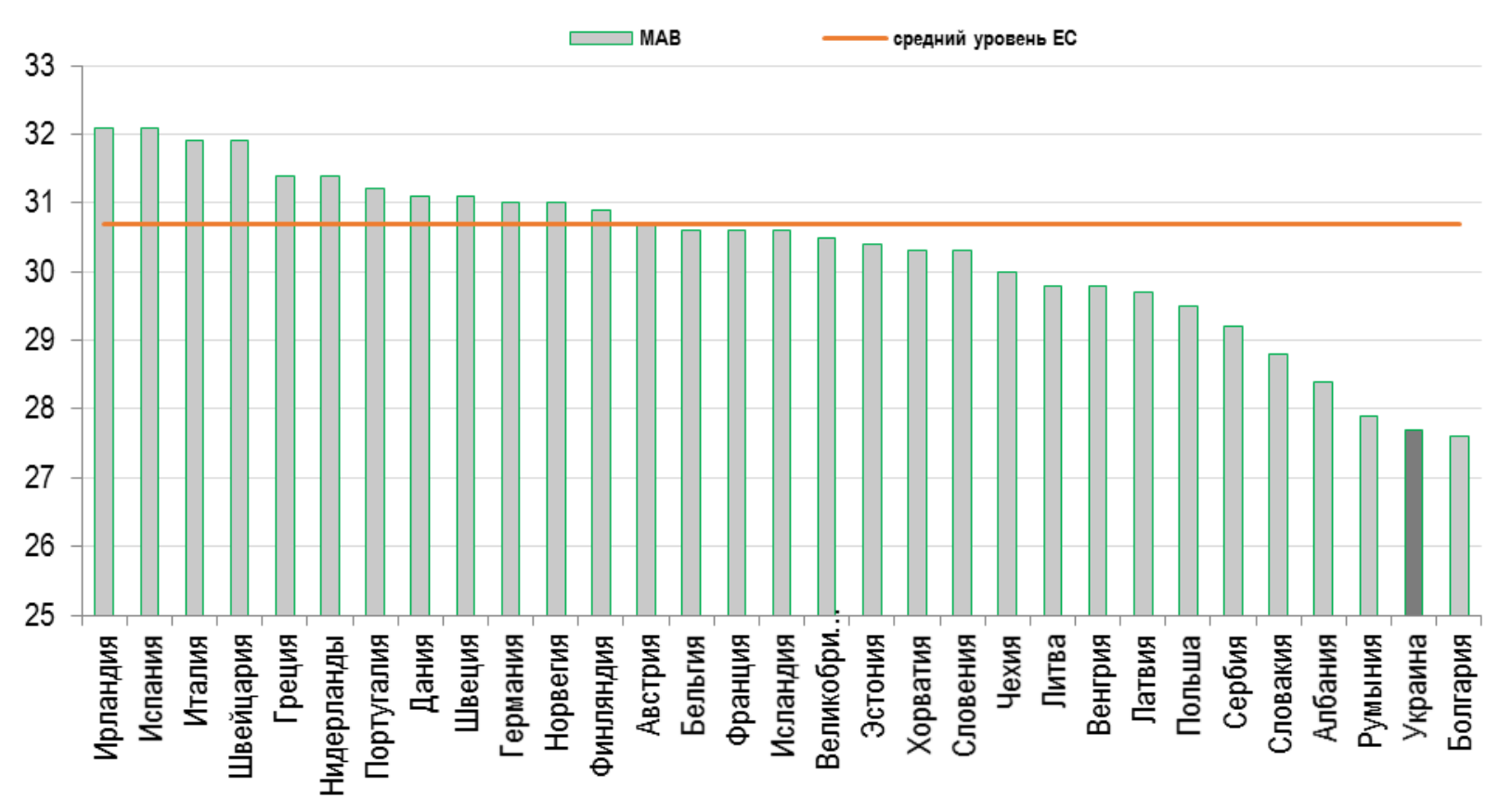

\section{Рисунок 2. Средний возраст матери при рождении ребенка в европейских странах} в 2017 г.

Источник: European Commission Database, https://ec.europa.eu/eurostat/data/database

Ф.Билари, А.Лифброер, Д.Филиппов (Billari F., Liefbroer A. \&, Philipov D.) откладывание рождения детей на старший возраст рассматривают как важный элемент теории второго демографического перехода. По мнению ученых, развитию этой тенденции в немалой степени способствовало изменение мировоззренческих установок, что отразилось в усилении стремления к индивидуальной автономии, неприятии институционального контроля, повышении значимости потребностей высоких уровней [3]. Откладывание деторождения также связывают с ростом человеческого капитала женщин, актуализацией вопросов гендерного равенства, повышением уровня политически обусловленной неопределенности. Изменение мировоззрения, ценностей и их иерархии могли стать фундаментом для повышения образовательного уровня, профессионального роста и самореализации через построение карьеры, основой для формирования установок сначала обеспечить необходимые для жизни условия, а уже потом рожать и воспитывать детей, или осознанно подбирать институты, участвующие в процессе обучения и воспитания детей. Наряду с этим могут измениться установки относительно желаемого числа детей в своей семье, лучшие интервалы между их рождениями.

Перечисляя основные факторы повышения возраста материнства, М.Миллс, Р.Риндфус и П.Макдональд (M.Mills, R.Rindfuss \& P.McDonald), прежде всего, указывают распространение образования и повышение уровня занятости женщин [5]. Заметим, что у многих исследователей такие факторы как образование, занятость, карьера, благосостояние стоят в одном ряду и неотделимы друг от друга. Особенно ярко их взаимосвязь прослеживается при изучении социальных и экономических последствий деторождения у девушек в подростковом возрасте. Рождение ребенка для несовершеннолетних матерей, как правило, создает препятствия для повышения уровня образования, что, в свою очередь, не позволяет найти высокооплачиваемую работу, снижает конкурентоспособность на рынке труда, затрудняет построение успешной карьеры, увеличивает вероятность бедности или малообеспеченности. Не случайно сокращение подростковой рождаемости включено в число задач, решение которых является важным для достижения Целей устойчивого развития. Многие организации в США настойчиво отстаивают идею, что женщины должны 
откладывать рождение ребенка до момента надлежащего устройства собственной жизни, когда они способны быть полностью ответственными как за свою жизнь, так и за жизнь своих детей. В этом контексте повышение возраста материнства является позитивной тенденцией современной трансформации рождаемости в Украине.

Начиная с 2009 г., коэффициенты рождаемости у 15-19-летних женщин в Украине постоянно уменьшались. В результате, за последнее десятилетие детородная активность самой молодой репродуктивной группы женщин снизилась на 38\%, и в 2018 г. составила $19,7 \%$, что более чем в 3 раза ниже уровня рождаемости у женщин этой возрастной группы в начале 1990-х годов. Однако, по сравнению с развитыми европейскими странами показатель подростковой рождаемости в Украине остается на высоком уровне: он в 2,6 раза превышает аналогичный показатель во Франции, Португалии, Германии, в 4 раза выше, чем в Италии, Швеции, Финляндии, в 7,4 раза выше уровня в Нидерландах (по данным Eurostat, 2017).

Многие исследования, основывающиеся на подходе семейной экономики Г.Беккера и его последователей, сосредотачивают внимание на упущенных из-за рождения ребенка возможностях для женщин-матерей. Вполне логично ожидать, что с возрастом женщины уровень её доходов повышается, например, благодаря профессиональному росту, приобретению опыта, переходу на высокооплачиваемую работу. С этих позиций, откладывание рождения детей может способствовать увеличению заработков и доходов. Так, в работах А.Миллер показано, что каждый год откладывания рождения ребенка приводит к увеличению доходов на 9-10\% (соответственно исследования 2005 и 2011 гг.) и ставки заработной платы на 3\% [4]. Однако, одновременно рождение ребенка в позднем возрасте способно увеличить и упущенные возможности в связи с необходимостью определенную часть времени уделять воспитанию ребенка/детей. Как правило, у женщин происходит снижение заработка во время рождения и ухода за первенцем и выравнивание профиля заработной платы в период всего материнства.

Существует мнение, что переход от семьи с одним кормильцем к модели семьи с двумя кормильцами, поощрение женщин принимать большее участие в трудовой жизни обусловили возрастание роли экономических условий в формировании репродуктивного поведения [6].

Важным фактором повышения возраста материнства / отцовства является экономическая нестабильность, быстрый рост конкуренции и неопределенности. В Украине в социологических опросах относительно факторов, из-за которых откладывается рождение ребенка или не реализуются в полной мере детородные планы, экономическая и политическая нестабильность указывались вслед за недостаточным материальным обеспечением и жилищной проблемой [2].

К настоящему времени существует целый ряд исследований, показывающих, что снижение для семьи «стоимости» содержания ребенка, благодаря увеличению пособий на детей и введению налоговых льгот, меняет календарь рождений и способствует некоторому омоложению материнства. К этому же выводу пришли демографы из Норвегии, но вместе с этим они предостерегли, что перенос рождений на молодой возраст, когда брачные (или партнерские) союзы с меньшей вероятностью будут формализованы или даже сформированы будет иметь неблагоприятные последствия [7].

Среди факторов повышения возраста материнства / отцовства следует также указать успехи современной медицины, что подтверждается снижением детской и материнской смертности, ростом разнообразия средств контрацепции, общедоступностью относительно безопасных и надежных методов контрацепции, распространением вспомогательных репродуктивных технологий, совершенствованием диагностики заболеваний в перинатальный период и т.д. Увеличивается доверие к медицинским инновациям: статистические данные показывают рост численности детей, рожденных с использованием вспомогательных репродуктивных технологий. Если в 2000 г. таких новорождённых было 
260, в 2005 г. - 1438 детей, то в 2017 г. уже 7596 детей родились живыми после использования лечебных циклов [1]. Однако здесь обнаруживается определенная парадоксальность: с одной стороны, успехи медицины позволяют женщине, принимая решение о рождении ребенка, «не привязываться» к возрасту и откладывать это событие с целью создания необходимых условий для воспитания ребенка. С другой стороны, с возрастом женщины постепенно ослабевает ее репродуктивная функция, возникают трудности с зачатием ребенка, что побуждает обращаться к вспомогательным репродуктивным технологиям. Поскольку стоимость таких процедур высокая, но только треть всех начатых лечебных циклов заканчиваются клинической беременностью, длительное откладывание рождения ребенка и последующая необходимость использования ВТР могут негативно отобразиться на финансовом благополучии семьи. Кроме этого, с возрастом увеличивается частота заболеваний, которые, как правило, не наблюдаются в молодом возрасте. Такие заболевания не только осложняют беременность, повышают риск для здоровья матери и ее будущего ребенка, но и могут привести к бесплодию, лечение которого потребует длительного времени.

Таким образом, откладывание рождения детей на старший возраст - одна из ключевых характеристик рождаемости последних десятилетий в Украине. Социальный аспект повышения возраста материнства проявляется в стремлении молодых женщин получить образование, начать профессиональную карьеру, достичь определенного материального уровня, и лишь после этого сосредоточиться на воспитании детей. Подобная последовательность событий способствует росту благополучия семьи, но важно учитывать и то обстоятельство, что длительное откладывание рождения детей и необходимость неоднократных обращений к дорогостоящим вспомогательным репродуктивным технологиям могут негативно повлиять на достигнутое финансовое благополучие.

\section{Библиография}

1. Заболотько В.М. Інформаційно-статистичний довідник про допоміжні репродуктивні технології в Україні. Київ : ДЗ «Центр медичної статистики МОЗ України», 2017, 28 с.

2. Молодь та молодіжна політика в Україні: соціально-демографічні аспекти. За ред. Е.М.Лібанової. К.: Інститут демографії та соціальних досліджень ім. М.В. Птухи НАН України, 2010, 248 с.

3. Billari F.C., Liefbroer A.C., and Philipov D. The Postponement of Childbearing in Europe: Driving Forces and Implications. Vienna Yearbook of Population Research, 2006, p. 1-17.

4. Miller A.R. The Effects of Motherhood Timing on Career Path. J Popul Econ, 2011, 24: 1071. https://doi.org/10.1007/s00148-009-0296-X,

http://theunbrokenwindow.com/Research\%20Methods/fertilitytiming-miller.pdf.

5. $\quad$ Mills M., Rindfuss R., McDonald P. Why do people postpone parenthood? Reasons and social policy incentives. Human Reproduction Update. 2011, Vol.17, No.6, p. 848-860.

6. Orsal D., Goldstein J. The Increasing Importance of Economic Conditions on Fertility. MPIDR Working Paper WP 2010-014. Max Planck Institute for Demographic Research, Rostock, Germany. February 26, 2010.

7. Taryn Ann Galloway, Rannveig Kaldager Hart. Effects of income and the cost of children on fertility: Quasi-experimental evidence from Norway. Statistics Norway, Research Department. Discussion Papers, November, 2015, No. 828. 